\title{
Epigenetic markers for early detection of nasopharyngeal carcinoma in a high risk population
}

\author{
Susanna H Hutajulu', Sagung R Indrasari ${ }^{1}$, Luh PL Indrawati ${ }^{1}$, Ahmad Harijadi ${ }^{1}$, Sylvia Duin², Sofia M Haryana ${ }^{1}$,
} Renske DM Steenbergen ${ }^{2}$, Astrid E Greijer ${ }^{2}$ and Jaap M Middeldorp ${ }^{2^{*}}$

\begin{abstract}
Background: Undifferentiated nasopharyngeal carcinoma (NPC) is strongly related to Epstein-Barr virus (EBV) infection, allowing aberrant antibodies against EBV and viral DNA load as screening tools in high risk populations. Methylation analysis in the promoter of tumor suppressor genes (TSGS) may serve as a complementary marker for identifying early cases. This study determined methylation status of multiple TSGs and evaluated whether it may improve early detection.
\end{abstract}

Methods: Nasopharyngeal brushings were taken from 53 NPC patients, 22 high risk subjects and 25 healthy EBV carriers. Corresponding NPC paraffin tissue was included. DNA was bisulfite-modified preceding analysis by methylation-specific PCR (MSP). Ten TSGs were studied.

Results: NPC paraffin and brushing DNA revealed an $81.8 \%$ concordance so that MSP analysis was done using either one of both specimens. NPC samples showed methylation for individual TSGs (DAPK1 79.2\%, CDH13 77.4\%, DLC1 76.9\%, RASSF1A 75.5\%, CADM1 69.8\%, p16 66.0\%, WIF1 61.2\%, CHFR 58.5\%, RIZ1 56.6\% and RASSF2A 29.2\%). High risk individuals, having elevated EBV IgA and viral load, showed high frequency of methylation of CDH13, DAPK1, DLC1 and CADM1, but low frequency of methylation of p16 and WIF1 and undetectable methylation of RASSF1A, CHFR, RIZ1 and RASSF2A. Healthy subjects showed similar patterns as high risk individuals. A combination of RASSF1A and p16 gave good discrimination between NPC and non-NPC, but best results were combined analysis of five methylation markers (RASSF1A, p16, WIF1, CHFR and RIZ1) with detection rate of 98\%.

Conclusion: Multiple marker MSP is proposed as a complementary test for NPC risk assessment in combination with EBV-based markers.

\section{Background}

Nasopharyngeal carcinoma (NPC) is highly prevalent in Southern China and South-East Asia. The incidence of NPC in Indonesia is 6.2 cases $/ 100,000$ population per year representing the fourth most common cancer [1]. Based on size of the Indonesian population it is estimated that 13,000 new cases of NPC occur annualy. Early detection is needed to improve patient survival since the majority of cases are currently diagnosed at late stage.

\footnotetext{
* Correspondence: j.middeldorp@vumc.nl

2Department of Pathology, VU University medical center, Amsterdam, The Netherlands

Full list of author information is available at the end of the article
}

Given the close link between NPC and Epstein-Barr virus (EBV) infection, detection of characteristic antibodies against EBV and elevated viral load has been proposed as useful screening tool [2-4]. Recently, we started a screening protocol in the Yogyakarta region recruiting high risk patients with chronic problems in the head and neck area and testing them using EBV-based assays. Although this study is still ongoing, current observations indicate that neither method provides an adequate stand-alone marker for detecting NPC as a primary screening test due to their relative low positive predictive value (PPV) (Hutajulu et al., unpublished data) confirming other reports $[5,6]$. The low PPV might be due to the large number of subjects presenting with elevated

\section{Ciomed Central}


EBV antibody levels and viral load that showed no clinical mass. Indeed, antibody levels against EBV were shown to be elevated for as long as ten years before tumor presentation [4]. As a consequence, recruitment of subjects by EBV-based markers alone would require long term monitoring. CT-scan examination and nasopharyngeal biopsy are needed for clinical confirmation of tumor presence. This would imply that a huge number of people would need detailed examination resulting in unacceptably high costs. It is therefore essential to define additional NPC progression markers for better selection of high risk patients.

Exploration of altered cellular genes involved in NPC development may provide a complementary test for risk assessment in EBV infected individuals. Promoter DNA methylation is widely considered to be an important epigenetic mechanism in carcinogenesis. In NPC, gene silencing by promoter methylation has been shown for multiple tumor suppressor genes (TSGs). Each TSG potentially contributes to the multistep oncogenesis including alterations of apoptosis, cell cycle and mitotic checkpoint regulation, intracellular adhesion, cytoskeleton organization, and Wnt-signalling pathway [7-9]. Therefore, in the present study we determined the frequency of promoter DNA methylation of multiple genes in Indonesian NPC cases. These TSGs were proven to be frequently methylated in NPC from other ethnic groups [10-16]. To analyse their potential value for detection of early-stage NPC, we compared the methylation pattern of NPC patients, healthy EBV carriers and a high risk population. The latter group consisted of patients with chronic head and neck complaints showing elevated EBV markers. Furthermore, we analysed an additional TSG, the myelin and lymphocyte-associated protein (MAL), which has been proven methylated in head and neck cancer [17] but has not been tested in NPC. More importantly, MAL gene is frequently methylated in cervical cancer indicating its role in virusrelated epithelial malignancy [18].

\section{Results}

\section{EBV IgA ELISA seroreactivity}

The antibody reactivity against EBV antigens was determined for all NPC, high risk and normal subjects. Elevated responses were seen in 49 NPC cases (92.5\%) and 3 normal subjects (12\%). A high risk group was defined $(\mathrm{n}=22)$ by selecting patients who visited the ear, nose and throat (ENT) department and showed chronic symptoms in the head and neck region $(\mathrm{n}=212)$. All selected subjects from this population had elevated EBV IgA ELISA seroreactivity and detectable viral load in their nasopharyngeal brushings. The ELISA results of the three groups are displayed in Figure 1. The seroreactivity of NPC patients and high risk individuals was

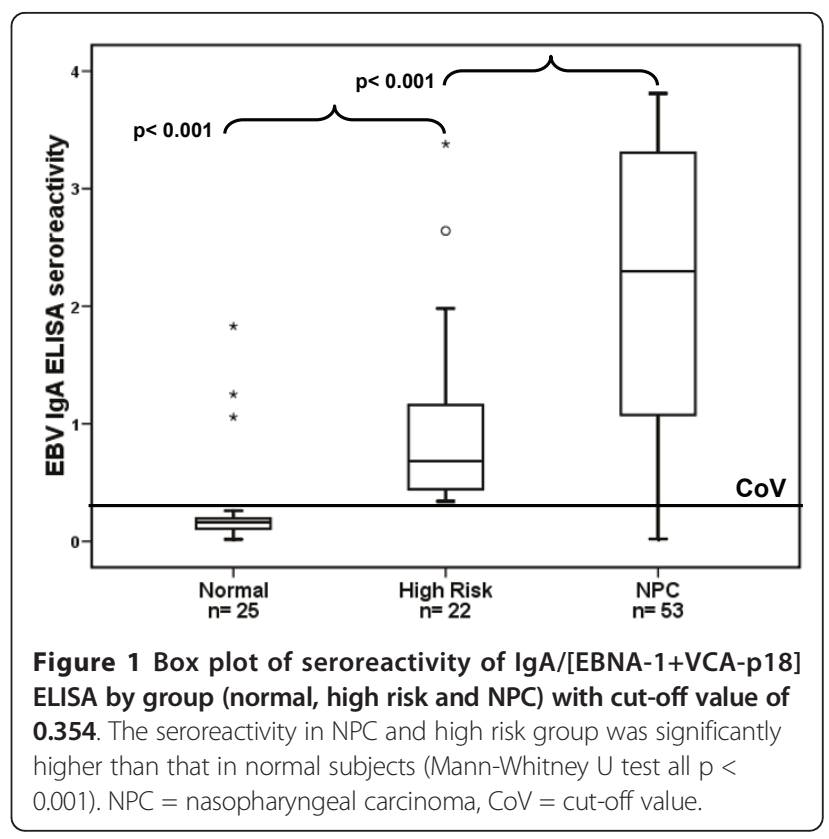

higher than that of healthy subjects and NPC cases showed higher responses compared to the high risk individuals (Mann-Whitney $\mathrm{U}$ test, all $\mathrm{p}<0.001$ ).

\section{EBV DNA quantity in nasopharyngeal brushings}

Quantitative analysis of EBV DNA was determined in brushing samples from 50 NPC patients, 22 high risk individuals and 25 healthy subjects. The viral load was detectable in 49 NPC (98\%) and all high risk isolates. In healthy subjects viral load was detectable in 4 cases $(16 \%)$ and below the cut-off value $(\mathrm{CoV})$ in 21 subjects (84\%). There was a significant difference between the median log of EBV DNA quantity in NPC, high risk and normal population $(\mathrm{p}<0.001)$ (Figure 2). The Post Hoc analysis using Tukey showed significant differences between NPC and high risk individuals as well as between NPC and normal EBV carriers (all p < 0.001).

\section{Nasopharyngeal carcinoma patient isolates showed frequent promoter methylation of 10 tumor suppressor genes}

For identification of methylation markers as complementary test for early detection of NPC, the frequency of promoter methylation of 10 TSGs was determined in NPC isolates. Identical methylation status in paraffin biopsy and the corresponding brushing samples was observed in 18 of 22 NPC cases, revealing an $81.8 \%$ overall agreement. Therefore methylation status in the NPC group was determined using either one of the two sample types. When determined in all isolates of NPC cases $(n=53)$ the frequency of promoter methylation of all individual genes ranged from 29.2-79.2\% (table 1). 


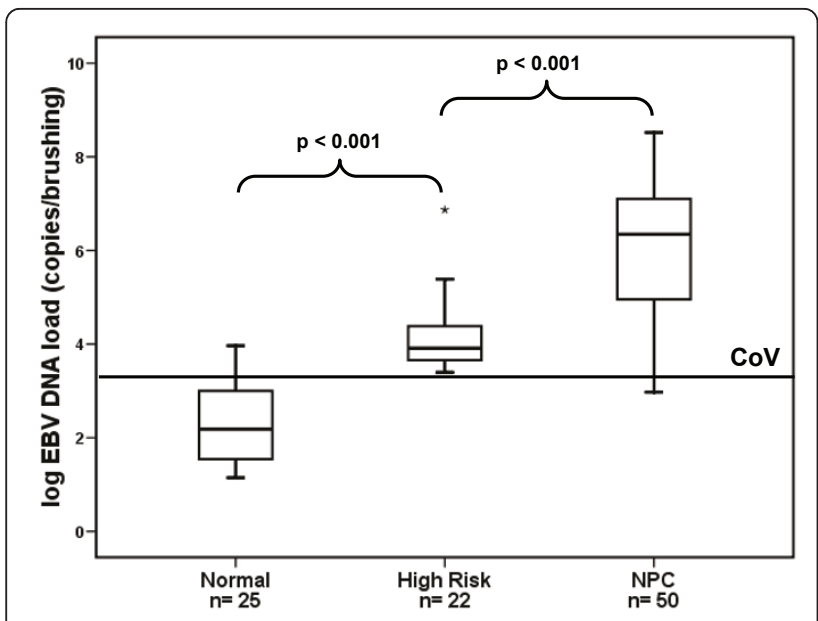

Figure 2 Boxplot of (log) EBV DNA load in nasopharyngeal brushings by group (normal, high risk and NPC). The cut-off value was set at $(\log )$ 2,300 copies/brushing (3.362). There were highly significant variations between median in the three groups (one-way ANOVA, $p<0.001$ ). Using Tukey analysis, the differrences between median in all groups are all significant. NPC = nasopharyngeal carcinoma, CoV = cut-off value.

Representative MSP pictures are shown in Figure 3. Fifty-two of 53 (98.1\%) NPC cases exhibited aberrant promoter methylation in at least one of the genes studied. Three (5.6\%) cases showed promoter methylation in all these genes. In one case (1.9\%) none of the genes was found to be methylated.

For analysis of the possibility of TSGs contributing to early stage NPC the frequency of promoter methylation in high risk and normal individuals was determined (table 1). In the high risk population methylation was detected for some TSGs including CDH13 (72.7\%), DAPK1 (40.9\%), CADM1 (36.4\%) and DLC1 (40.9\%). The frequency of methylation of p16 and WIF1 gene was low (27.2\% and $18.2 \%$ respectively), whereas methylation of CHFR, RIZ1, RASSF1A and RASSF2A gene was undetectable. In the normal population a high frequency of methylation was demonstrated for DAPK1 (48.0\%), CDH13 (64.0\%) and DLC1 (64.0\%), whereas methylation of CADM1 (72\%) was even higher than in NPC cases and high risk subjects. In healthy EBV carriers promoter methylation was very low for RASSF1A (4\%) and undetectable for CHFR, RIZ1, WIF1, p16 and RASSF2A. The high methylation frequency in healthy individuals led us to evaluate methylation patterns in 11 peripheral blood mononuclear cells (PBMC) from Dutch healthy donors and 5 spontaneous lymphoblastoid cell lines (LCL) from Indonesian healthy donors. In these specimens the methylation frequency of the particular genes was detectable but was not as high as that of nasopharyngeal brushing from healthy donors (DAPK1 18.8\%, DLC1 18.8\%, CDH13 31.3\% and CADM1 43.8\%, respectively). In contrast, RASSF1A, RIZ1, CHFR, WIF1, p16 and RASSF2A showed no detectable methylation (data not shown).

\section{Confirmation of methylation status using Q-MSP}

To determine whether the high frequency of CADM1 promoter methylation in the normal population was related to the level of methylation quantitative amplification was performed. Fifteen paraffin tissues and 18 brushings from NPC patients, 15 brushings from high risk and 11 brushings from normal individuals were selected for Q-MSP using Taqman. As shown in Figure 4A methylation levels of CADM1 were comparable between brushings of healthy controls, high risk subjects and NPC cases $(\mathrm{p}=0.654$ for healthy versus NPC and $\mathrm{p}$ $=0.641$ for NPC versus high risk), confirming the MSP result. NPC paraffin yielded higher methylation levels compared to NPC brushing but the difference was not significant $(\mathrm{p}=0.069)$.

\section{MAL promoter methylation showed good discrimination between NPC and normal subjects}

In parallel to CADM1 we analysed MAL promoter methylation which was shown to be relevant in the viral oncogenesis of cervical cancer (Figure 4B). Better

Table 1 The frequency of gene promoter methylation of 10 tumor suppressor genes in NPC, high risk and normal subjects.

\begin{tabular}{llll}
\hline Gene & NPC group (paraffin and/or brushing) & High Risk Group (brushing) & EBV-normal carriers (brushing) \\
\hline CHFR & $31 / 53(58.5 \%)$ & $0 / 22(0.0 \%)$ & $0 / 25(0.0 \%)$ \\
RIZ1 & $30 / 53(56.6 \%)$ & $0 / 22(0.0 \%)$ & $0 / 25(0.0 \%)$ \\
WIF1 & $30 / 49(61.2 \%)$ & $4 / 22(18.2 \%)$ & $0 / 25(0.0 \%)$ \\
P16 & $35 / 53(66.0 \%)$ & $6 / 22(27.2 \%)$ & $0 / 25(0.0 \%)$ \\
RASSF2A & $14 / 48(29.2 \%)$ & $0 / 22(0.0 \%)$ & $0 / 25(0.0 \%)$ \\
RASSF1A & $40 / 53(75.5 \%)$ & $0 / 22(0.0 \%)$ & $1 / 25(4.0 \%)$ \\
DAPK1 & $42 / 53(79.2 \%)$ & $9 / 22(40.9 \%)$ & $12 / 25(48.0 \%)$ \\
DLC1 & $40 / 52(76.9 \%)$ & $9 / 22(40.9 \%)$ & $16 / 25(64.0 \%)$ \\
CDH13 & $41 / 53(77.4 \%)$ & $16 / 22(72.7)$ & $16 / 25(64.0 \%)$ \\
CADM1 & $37 / 53(69.8 \%)$ & $8 / 22(36.4 \%)$ & $18 / 25(72.0 \%)$ \\
\hline
\end{tabular}

In NPC group methylation status was determined either from paraffin or brushing DNA.

Frequency is presented in order of percentage in EBV-normal group from the smallest to the largest 


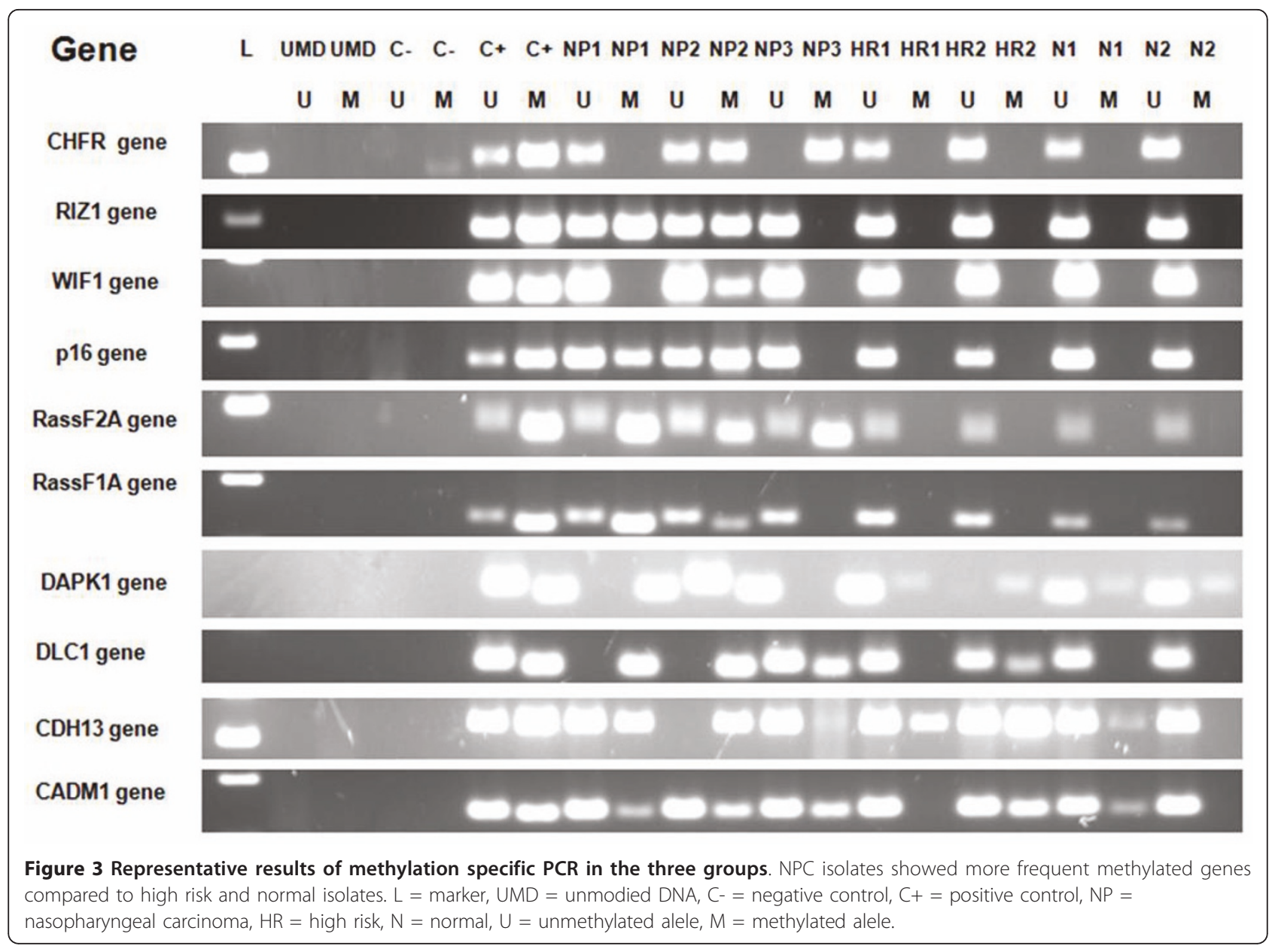

discriminating levels of methylation were demonstrated in NPC brushing compared to brushing from healthy EBV carriers $(p=0.070)$. The level of MAL methylation in NPC paraffin and NPC brushing was similar $(\mathrm{p}=0.315)$ but in NPC paraffin it was significantly higher compared to brushing samples from healthy persons $(\mathrm{p}=0.002)$. This indicates that MAL methylation status may be a promising additional marker for NPC detection.

A panel of 5 methylated TSGs showed best discrimination between NPC and non-cancer individuals

In Indonesian NPC cases all 10 TSGs tested with MSP showed high frequency of promoter methylation. However when comparing the three study groups, not all TSGs allowed discrimination of NPC cases from nonNPC individuals. Thus, defined genes were selected as NPC markers with high methylation frequency including CHFR, RIZ1, WIF1, p16 and RASSF1A. NPC isolates showed methylation detection of 58.5-75.5\% for these genes compared to almost undetectable frequency in normal EBV carriers and partly methylated in the high risk group (table 1). By using this panel of 5 markers the NPC detection rate was improved compared to the individual markers. The sensitivity and specificity of using at least one of the markers (analysed in 50 NPC cases versus 25 normal subjects) are $98 \%$ and $96 \%$, respectively. By using 2 markers with the highest frequency (RASSF1A and p16 gene), the sensitivity and specificity of at least one of both are $91 \%$ and $96 \%$, respectively.

\section{Correlation of methylation status with other parameters}

The frequency of methylation was tested in relation to EBV parameters and age. There was a significant correlation between the rate of methylation with EBV DNA load $(\mathrm{r}=0.322, \mathrm{p}=0.023)$ (Figure $5 \mathrm{~B}$ ), but not with EBV IgA ELISA seroreactivity $(r=-1.88 \mathrm{p}=0.117)$ (Figure $5 \mathrm{~A})$ and age $(\mathrm{r}=0.270, \mathrm{p}=0.05)$ (Figure $5 \mathrm{C})$. When considering one outlier, methylation has a significant correlation with age $(\mathrm{r}=0.369, \mathrm{p}=0.007)$. The outlier was a young patient from a rare multiplex NPC family.

\section{Discussion}

Methylation of promoter DNA is considered an important epigenetic event in NPC carcinogenesis [7-9] and 

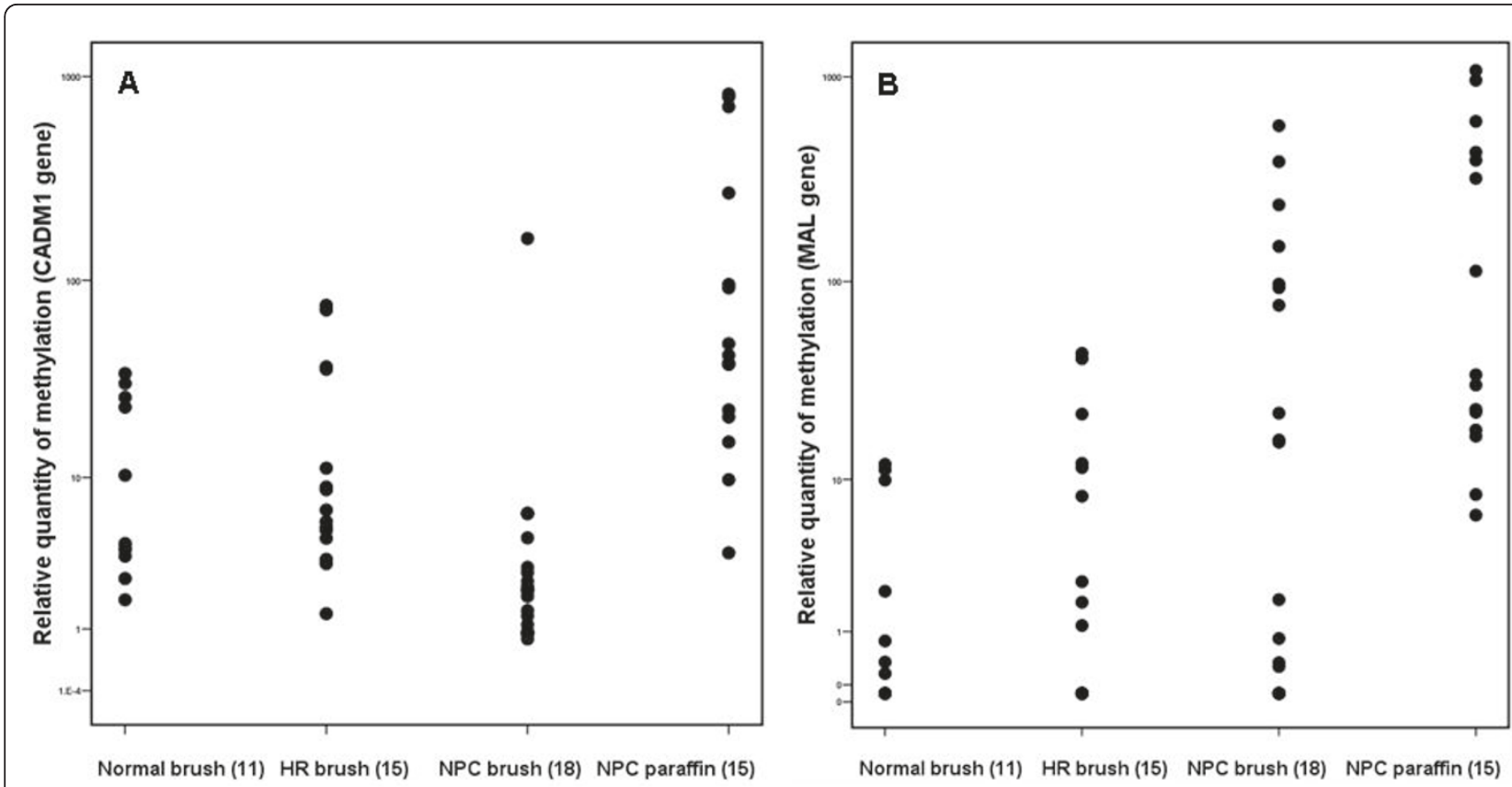

Figure 4 Scatter diagram of relative quantity of methylation of (A) CADM1 and (B) MAL gene. The $Y$ axis is expressed in log scale. CADM1 (A) showed an insignificant variations between normal brushing and NPC brushing and between NPC brushing and NPC paraffin (oneway ANOVA using Tukey analysis $p=0.654$ and 0.069 respectively). Thus Q-MSP confirmed the result of MSP. MAL (B) showed insignificant variations between normal brushing and NPC brushing $(p=0.070)$. Methylation level in NPC paraffin was comparable to NPC brushing ( $p=$ 0.069) but was significantly higher compared to normal brushing $(p=0.002)$ indicating that MAL methylation can be a promising marker for NPC detection. HR = high risk, NPC = nasopharyngeal carcinoma.

has been proven promising for diagnosis of multiple type of tumors $[18,19]$. Since the profile of TSG promoter methylation may vary according to tumor type [20], this study defined epigenetic variability in NPC. Aberrant methylation of five TSGs was identified as independent marker for early detection of NPC with added value to EBV IgA serology and DNA load. For a developing country like Indonesia such a test should be economical with simple but well standardized technology suited for screening in a large population. Therefore qualitative MSP is proposed, being less labor-intensive and inexpensive compared to other assays such as QMSP or bisulfite sequencing.

We selected a set of markers that have been evaluated in various NPC populations. Since methylation changes have been reported to occur early in carcinogenesis [7], epigenetic markers are potentially relevant as early indicators of subclinical presence of NPC. Our present study demonstrated that the promoter methylation frequency of individual TSGs is variable in NPC, confirming previous publications [10-16]. The methylation frequency of single genes varied from 29.2\% (RASSF2A gene) to $79.2 \%$ (DAPK1 gene). This frequency is comparable to the one presented in other studies except for WIF1 [12] and RASSF2A [14] where the frequency in the Indonesian samples was much lower $(61.2 \%$ and $29.2 \%$, respectively).

For particular genes (DAPK1, CADM1, CDH13 and DLC1), the methylation frequency is not only high in NPC cases, but also in the high risk group and normal EBV carriers, thus limiting their diagnostic value. The high frequency of methylation has not been reported before in other healthy control populations, mostly showing a frequency below $10 \%[15,16,21,22]$. However, the occurrence of methylation in normal tissue was confirmed in PBMCs and LCLs obtained from healthy individuals. In CADM1, the high frequency of methylation detected by MSP was explained by frequent but low level methylation in both normal and NPC brushing using Q-MSP. This suggested that CADM1 is not a good marker for the early detection of NPC. Similarly DAPK1, CDH13 and DLC1 could be considered as nonspecific markers.

A panel of methylation markers consisting of CHFR, RIZ1, p16, WIF1 and RASSF1A is proposed as a complementary test for early NPC detection. These five TSGs showed high methylation in NPC cases and not more than $4 \%$ in the regional healthy EBV positive controls providing good differentiation between cancer cases and normal controls. Detection of aberrant 

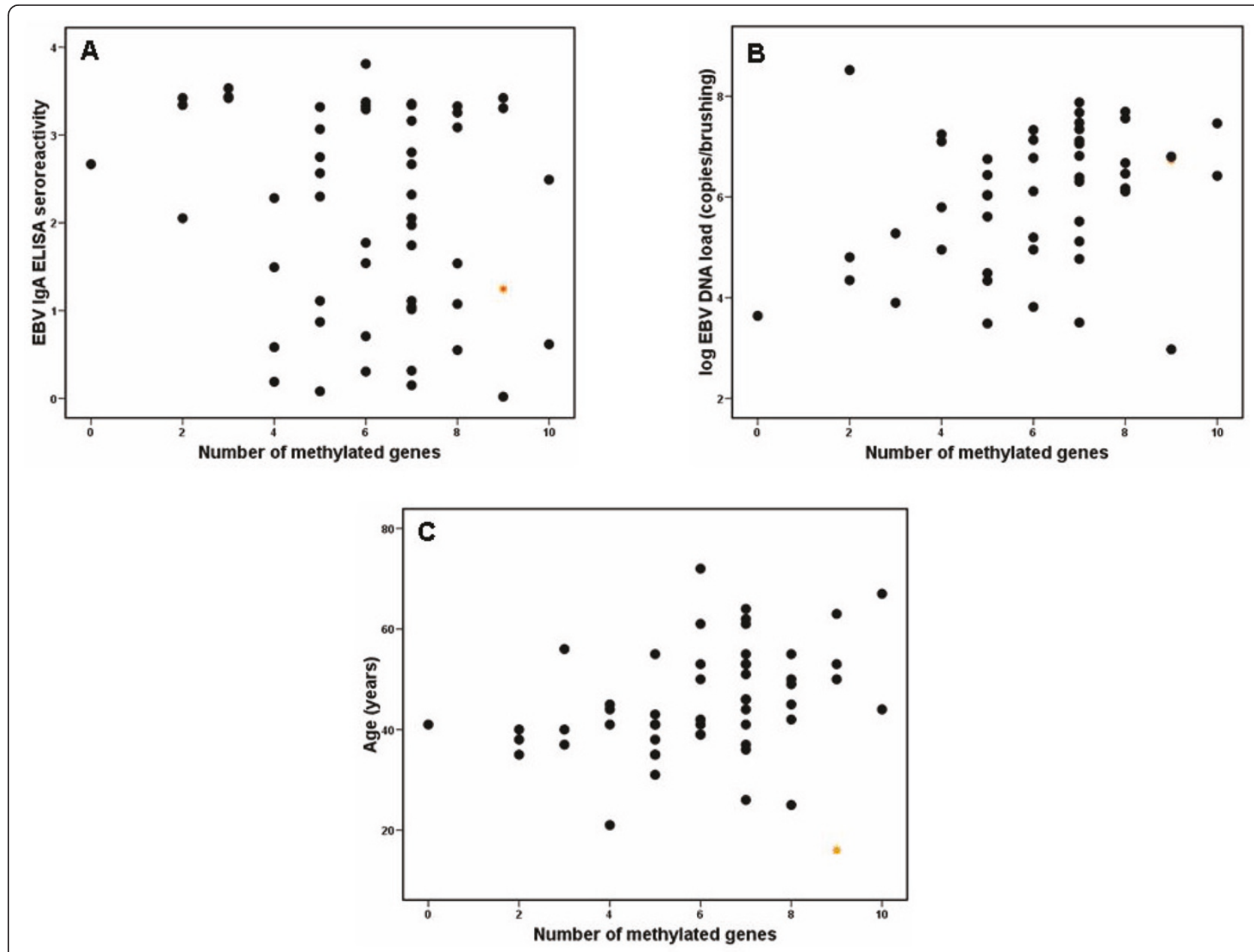

Figure 5 Scatter diagram of (A) ELISA seroreactivity on 53 NPC sera, (B) log EBV DNA load on 50 NPC brushings and (C) age of 53 NPC cases versus number of methylated tumor suppressor genes. The correlation with methylation rate is significant but weak for EBV DNA load (Pearson correlation $r=0.322, p=0.023$ ) and insignificant for ELISA seroreactivity $(r=-1.88 p=0.117)$ and age $(r=0.270, p=0.05)$. The latter becomes significant when excluding a young patient from a multiplex family (symbolized with star) $(p=0.007)$.

methylation in at least one of this panel showed a rate of $98 \%$ in NPC group compared to individual markers. In particular, detection of aberrant methylation of p16 and RASSF1A may provide more simple testing with specificity and sensitivity above $90 \%$.

Pilot testing of MAL methylation using Q-MSP revealed this gene as an additional discriminator between NPC and normal controls. As explored previously in cervical [18] the MAL gene may play a specific role in viral-epithelial malignancies. Since the MAL gene has not been analysed in NPC before, this report is the first to describe it as a promising marker for further investigation.

Comparing paraffin tissue and brushing samples of NPC cases revealed a good detection of methylation for both sample types, supporting the results of Sun et al. [16]. Nasopharyngeal brushing is proposed for sampling in population screening studies considering it is convenient and simple. When determined only on brushing samples, methylation of any marker of the selected genes was detected in 39 out of 41 NPC cases (95.1\%). This is comparable to the assessment using either paraffin or brushing which detected methylation in $98 \%$ of NPC. Moreover, this minimal invasive procedure yielded high PPV (>90\%) compared to biopsy and reproducible high yields of cellular DNA $\left(10^{6}-10^{7}\right.$ genome copies/ brush). Nasopharyngeal brushing is also an excellent sampling method for monitoring EBV DNA load and EBV mRNA expression, each having good diagnostic value [23].

Our present study did not demonstrate a significant difference between methylation frequency in early and late stage NPC cases (data not shown). To evaluate the capacity of epigenetic markers to detect preclinical 
disease, a longitudinal study is currently in progress in the local high risk population. Compared to the baseline observation, this cohort revealed an increased frequency of methylation of p16 and RIZ1. The presence of p16 methylation supports previous reports showing p16 gene silencing in precancerous lesions of NPC. However our data do not confirm RASSF1A methylation in premalignant tissues [7]. This indicates that epigenetic changes leading to malignancy in the Indonesian population may differ from other populations. Which gene silencing event initiates NPC development and which contributes to further progression of the multistep carcinogenic process remains to be investigated.

The correlation found between methylation status and viral DNA load in Indonesian NPC cases indicates a link between epigenetic events and EBV infection. The appropriate level of DNA load in our NPC samples may directly reflect a (pre)malignant process. This is in agreement with a previous data on matched NPC tumor and adjacent tissues. The nearer to the NPC tissue, the higher the levels of gene promoter methylation and EBV DNA load found [11]. More recent studies implied the role of EBV genes in epigenetic silencing either through activation of DNA methyltransferases [24] or interaction with transcriptional repression [25].

Factors known to contribute to methylation alterations include age, diet and lifestyle [26,27]. Regarding the factor of age, our result on Indonesian NPC showed a tendency for methylation frequency to increase with age. This reflects accumulative epigenetic events under the influence of environmental exposures that may increase with time. Considering the factor of diet, our observation in the local population demonstrates that diet might also predispose one towards cancer development. Formaldehyde, boric acid, Rhodamine B, and yellow Metanyl are among many reported chemicals found in the food of local markets in Indonesia [28]. Persistent exposure to environmental toxins is indicated as an initial step of epigenetic alteration preceding cancer development [29-31]. This might explain the high frequency of methylation of certain genes observed in the Indonesian healthy population. The potential relationship between carcinogenic exposure and promoter methylation status is subject to further study. Analysis of the methylation status of selected genes is proposed as additive test for NPC risk assessment using EBV-based assays in primary screening. The epigenetic markers described here provide complementary information in a subgroup of high risk individuals with aberrant EBV IgA seroreactivity and elevated viral load. In a case-finding approach, screening subjects presenting with symptoms suspicious of NPC, this approach may identify those subjects at highest risk of NPC development.

\section{Conclusion}

Indonesian NPC cases showed more frequent methylated TSGs compared to high risk and normal individuals implicating epigenetic changes in NPC development and suggesting their utility for NPC identification. DNA promoter methylation of defined sets of genes may serve as a complementary test for early NPC detection in combination with EBV-based markers. Such a test should include p16 and RASSF1A possibly combined with CHFR, RIZ1, WIF1 and MAL.

\section{Materials and methods}

\section{Patients and biological samples}

Paraffin-embedded tissue from 34 NPC patients before treatment were selected from the pathology archives of Dr. Sardjito Teaching Hospital Yogyakarta [23]. Corresponding nasopharyngeal brushings were collected from 22 of these patients. Single nasopharyngeal brushing samples from 19 NPC cases were obtained yielding 53 overal NPC cases. NPC cases were histologically confirmed as undifferentiated NPC (WHO type 3). Presence of EBV was confirmed by EBV-encoded small RNA (EBER) detection in all cases [23]. Staging was done according to the AJCC 2004 criteria with 44 patients $(80 \%)$ at late stage NPC (3 or 4 ) and 9 patients at early stage (1 or 2 ). Twenty-two individuals with chronic symptoms suggestive for early NPC [4] and having elevated EBV markers were selected as the high risk population. Twenty-five asymptomatic EBV carriers were recruited consisting of 9 Dutch and 16 Indonesian subjects. All participants were recruited with informed consent to give blood and nasopharyngeal brushings.

\section{DNA extraction and bisulfite modification}

Genomic DNA from nasopharyngeal brushings was isolated using silica-based extraction [32] (Basic kit, BioMerieux, Boxtel, The Netherlands). DNA isolation from paraffin-embedded tissue was performed using the Chelex method [33]. Of each DNA sample 500 ng was used for bisulfite treatment using a commercially available DNA modification kit (EZ DNA Methylation Kit ${ }^{\mathrm{TM}}$; Zymo Research, Orange, CA, USA).

\section{EBV markers}

EBV specific IgA reactivity was assessed in all sera by a synthetic peptide based enzyme-linked immunosorbent assay (ELISA) for immunodominant epitopes derived from Epstein-Barr virus nuclear antigen 1 (EBNA-1) and viral capsid antigen (VCA)-p18 (further referred to as EBV IgA ELISA). The ELISA CoV was 0.354 as previously defined [34]. EBV DNA load in nasopharyngeal (NP) brushings was determined by quantitative LightCycler (LC) real-time PCR targeting a 213 bp conserved 
region of EBNA-1 [35]. The CoV was set on 2,300 copies/brushing presenting the mean $+3 * \mathrm{SD}$ of a cohort of controls [23].

\section{Methylation-specific PCR (MSP) and quantitative MSP (Q- MSP)}

MSP targeted regions within promoters of 10 TSGs including CHFR [36], RIZ1 [37], WIF1 [12], p16 [38], RASSF1A [39], RASSF2A [40], DAPK1 [41], DLC1 [15], CDH13 [42] and CADM1 [43]. The sequences of PCR primers specific for unmethylated and methylated alleles of all targets were identical as previously published. FastStart Taq PCR and Amplitaq Gold (Roche Diagnostics Netherlands BV) were used for ampification. The EBV positive Burkitt's lymphoma cell line (Namalwa), EBV negative nasopharyngeal carcinoma cell line (HONE-1), cervical cancer cell lines (CaSki, SiHa), human lung adenocarcinoma cell line (Calu-6), human colon carcinoma cell line (RKO) and primary human foreskin keratinocytes (EK) were included as positive and negative PCR controls for either unmethylated or methylated amplification. For these cell lines methylation status of individual TSGs was known $[10-12,15,16,44]$. As negative controls, $\mathrm{H}_{2} \mathrm{O}$, bisulfite modified DNA of primary keratinocytes and unmodified methylated DNA from cell lines or brushing samples were included.

Quantitative-MSP (Q-MSP) was conducted using primer sets targeting the CADM1 and the MAL gene promoter. Amplicons were detected and quantified using Taqman probes. Primer/probe sequence for CADM1 is (forward) ATTTTATTACTTCTTCGTTCGGGT, (probe) ACCTACCTCAAACTAACGACGTTAACTACCTCCGA and (reverse) CTCGACAACACTACACTCGCC [45]. The Q-MSP amplicon largely overlaps the conventional MSP amplicon (CADM1 region M9) [43]. Primer/ probe sequences for the MAL promoter were described previously [18]. Q-MSP was set up using QuantiTect Probe PCR Kit master mix (Qiagen, Westburg, Leusden, The Netherlands). For each Q-MSP a standard curve consisting of serial dilutions of bisulfite-treated DNA of the SiHa cervical cell line was used. The housekeeping gene $\beta$-actin was applied as an internal reference. To determine the relative quantity of methylation, ratios between methylated CADM1 or MAL DNA versus $\beta$-actin DNA was performed (average quantity of methylated CADM1/MAL DNA/average DNA quantity for $\beta$-actin $\times 1000$ ).

\section{Statistical analysis}

Differences of methylation status between the three groups versus other diagnostic parameters were analysed using one-way analysis of variance (ANOVA) (EBV DNA load) or Mann-Whitney U test (ELISA seroreactivity). Differences of methylation status in Q-MSP were analysed using one-way ANOVA. The correlation between methylation status and ELISA seroreactivity, EBV DNA load and age was assessed using the Pearson correlation test. $\mathrm{p}<0.05$ was considered significant. All statistical calculations were performed using SPSS version 15.0.

\section{Acknowledgements}

We gratefully acknowledge Nuffic/Netherland Fellowship Program (NFP-PhD 08-36), Dutch Cancer Society (KWF IN-2004-17) and Risbinkes Iptekdok/ Ministry of Health Republic of Indonesia (2009) for grant fundings. We also would like to thank Bambang Hariwiyanto and Camelia Herdini for clinical support, Jarir Atthobari for statistical advice and Sumartiningsih, Renee M Overmeer, Debbie Claassen-Kramer and Sandra AWM Verkuijlen for technical assistance.

\section{Author details}

${ }^{1}$ Faculty of Medicine/Dr. Sardjito Hospital, Universitas Gadjah Mada, Yogyakarta, Indonesia. ${ }^{2}$ Department of Pathology, VU University medical center, Amsterdam, The Netherlands.

\section{Authors' contributions}

JMM conceived the study. SHH carried out the molecular work, statistical analysis, data interpretation and wrote the initial draft of the manuscript. SRI and LPLI participated in clinical sampling. $\mathrm{H}$ participated in sample selection and pathological expertise. SD carried out quantitative methylation-specific PCR and participated in data interpretation. SMH, RDS and AEG supervised the molecular work, participated in data interpretation and edited the manuscript. JMM and SHH had the primary responsibility for interpreting the data and editing the final manuscript. All authors provided comments of various drafts, participated in direction setting discussions and reviews and have read and approved the final version.

\section{Competing interests}

The authors declare that they have no competing interests.

Received: 26 November 2010 Accepted: 2 May 2011

Published: 2 May 2011

\section{References}

1. Soeripto: Epidemiology of nasopharyngeal carcinoma. Berita Kedokteran Masyarakat (Ina) 1998, XIII:207-211.

2. Chien YC, Chen JY, Liu MY, Yang HI, Hsu MM, Chen CJ, Yang CS: Serologic markers of Epstein-Barr virus infection and nasopharyngeal carcinoma in Taiwanese men. N Engl J Med 2001, 345:1877-1882.

3. Yang X, Goldstein AM, Chen CJ, Rabkin CS, Chen JY, Cheng YJ, Hsu WL, Sun B, Diehl SR, Liu MY, et al: Distribution of Epstein-Barr viral load in serum of individuals from nasopharyngeal carcinoma high-risk families in Taiwan. Int J Cancer 2006, 118:780-784.

4. Ji MF, Wang DK, Yu YL, Guo YQ, Liang JS, Cheng WM, Zong YS, Chan KH, $\mathrm{Ng}$ SP, Wei Wl, et al: Sustained elevation of Epstein-Barr virus antibody levels preceding clinical onset of nasopharyngeal carcinoma. $\mathrm{Br} J$ Cancer 2007, 96:623-630.

5. Chan KH, Gu YL, Ng F, Ng PS, Seto WH, Sham JS, Chua D, Wei W, Chen YL, Luk W, et al: EBV specific antibody-based and DNA-based assays in serologic diagnosis of nasopharyngeal carcinoma. Int J Cancer 2003, 105:706-709.

6. Ng WT, Choi CW, Lee MC, Chan SH, Yau TK, Lee AW: Familial nasopharyngeal carcinoma in Hong Kong: epidemiology and implication in screening. Fam Cancer 2009, 8:103-108.

7. Lo KW, Huang DP: Genetic and epigenetic changes in nasopharyngeal carcinoma. Semin Cancer Biol 2002, 12:451-462.

8. Tao Q, Chan AT: Nasopharyngeal carcinoma: molecular pathogenesis and therapeutic developments. Expert Rev Mol Med 2007, 9:1-24.

9. Chou J, Lin YC, Kim J, You L, XU Z, He B, Jablons DM: Nasopharyngeal carcinoma-review of the molecular mechanisms of tumorigenesis. Head Neck 2008, 30:946-963. 
10. Cheung HW, Ching YP, Nicholls JM, Ling MT, Wong YC, Hui N, Cheung A, Tsao SW, Wang Q, Yeun PW, et al: Epigenetic inactivation of CHFR in nasopharyngeal carcinoma through promoter methylation. Mol Carcinog 2005, 43:237-245.

11. Zhou L, Jiang W, Ren C, Yin Z, Feng X, Liu W, Tao Q, Yao K: Frequent hypermethylation of RASSF1A and TSLC1, and high viral load of EpsteinBarr Virus DNA in nasopharyngeal carcinoma and matched tumoradjacent tissues. Neoplasia 2005, 7:809-815.

12. Chan SL, Cui $Y$, van Hasselt A, Li H, Srivastava G, Jin H, Ng KM, Wang $Y$, Lee KY, Tsao GS, et al: The tumor suppressor Wnt inhibitory factor 1 is frequently methylated in nasopharyngeal and esophageal carcinomas. Lab Invest 2007, 87:644-650.

13. Kwong J, Lo KW, To KF, Teo PM, Johnson PJ, Huang DP: Promoter hypermethylation of multiple genes in nasopharyngeal carcinoma. Clin Cancer Res 2002, 8:131-137.

14. Zhang Z, Sun D, Van do N, Tang A, Hu L, Huang G: Inactivation of RASSF2A by promoter methylation correlates with lymph node metastasis in nasopharyngeal carcinoma. Int J Cancer 2007, 120:32-38.

15. Seng TJ, Low JS, Li H, Cui Y, Goh HK, Wong ML, Srivastava G, Sidransky D, Califano J, Steenbergen RD, et al: The major 8p22 tumor suppressor DLC1 is frequently silenced by methylation in both endemic and sporadic nasopharyngeal, esophageal, and cervical carcinomas, and inhibits tumor cell colony formation. Oncogene 2007, 26:934-944.

16. Sun D, Zhang Z, Van do N, Huang G, Ernberg I, Hu L: Aberrant methylation of $\mathrm{CDH} 13$ gene in nasopharyngeal carcinoma could serve as a potential diagnostic biomarker. Oral Oncol 2007, 43:82-87.

17. Cao W, Zhang ZY, Xu Q, Sun Q, Yan M, Zhang J, Zhang P, Han ZG, Chen WT: Epigenetic silencing of MAL, a putative tumor suppressor gene, can contribute to human epithelium cell carcinoma. Mol Cancer 2010, 9:296.

18. Overmeer RM, Henken FE, Bierkens M, Wilting SM, Timmerman I, Meijer CJ, Snijders PJ, Steenbergen RD: Repression of MAL tumour suppressor activity by promoter methylation during cervical carcinogenesis. J Pathol 2009, 219:327-336

19. Chen K, Sawhney R, Khan M, Benninger MS, Hou Z, Sethi S, Stephen JK, Worsham MJ: Methylation of multiple genes as diagnostic and therapeutic markers in primary head and neck squamous cell carcinoma. Arch Otolaryngol Head Neck Surg 2007, 133:1131-1138.

20. Esteller M, Corn PG, Baylin SB, Herman JG: A gene hypermethylation profile of human cancer. Cancer Res 2001, 61:3225-3229.

21. Wong TS, Kwong DL, Sham JS, Wei WI, Kwong YL, Yuen AP: Quantitative plasma hypermethylated DNA markers of undifferentiated nasopharyngeal carcinoma. Clin Cancer Res 2004, 10:2401-2406.

22. Lung HL, Cheung AK, Xie D, Cheng Y, Kwong FM, Murakami Y, Guan XY, Sham JS, Chua D, Protopopov Al, et al: TSLC1 is a tumor suppressor gene associated with metastasis in nasopharyngeal carcinoma. Cancer Res 2006, 66:9385-9392.

23. Stevens SJ, Verkuijlen SA, Hariwiyanto B, Paramita DK, Fachiroh J, Adham M, Tan IB, Haryana SM, Middeldorp JM: Noninvasive diagnosis of nasopharyngeal carcinoma: nasopharyngeal brushings reveal high Epstein-Barr virus DNA load and carcinoma-specific viral BARF1 mRNA. Int J Cancer 2006, 119:608-614.

24. Tsai CN, Tsai CL, Tse KP, Chang HY, Chang YS: The Epstein-Barr virus oncogene product, latent membrane protein 1, induces the downregulation of E-cadherin gene expression via activation of DNA methyltransferases. Proc Natl Acad Sci USA 2002, 99:10084-10089.

25. Skalska L, White RE, Franz M, Ruhmann M, Allday MJ: Epigenetic repression of $\mathrm{p} 16(\mathrm{INK} 4 \mathrm{~A})$ by latent Epstein-Barr virus requires the interaction of EBNA3A and EBNA3C with CtBP. PLoS Pathog 2010, 6:e1000951.

26. Marsit CJ, Houseman EA, Schned AR, Karagas MR, Kelsey KT: Promoter hypermethylation is associated with current smoking, age, gender and survival in bladder cancer. Carcinogenesis 2007, 28:1745-1751.

27. Brait M, Ford JG, Papaiahgari S, Garza MA, Lee Jl, Loyo M, Maldonado L, Begum S, McCaffrey L, Howerton M, et al: Association between lifestyle factors and CpG island methylation in a cancer-free population. Cancer Epidemiol Biomarkers Prev 2009, 18:2984-2991.

28. Kompas: 2006 [http://www.litbang.depkes.go.id/aktual/formalin/ formalin150106.htm], Sidney Morning Herald, 2006 http://www.smh.com.au/ news/World/Formaldehyde-food-scare-in-Indonesia/2006/01/09/ 1136771495164.html.
29. Li S, Hursting SD, Davis BJ, McLachlan JA, Barrett JC: Environmental exposure, DNA methylation, and gene regulation: lessons from diethylstilbesterol-induced cancers. Ann N Y Acad Sci 2003, 983:161-169.

30. Szende B, Tyihak E: Effect of formaldehyde on cell proliferation and death. Cell Biol Int 2010, 34:1273-1282.

31. Mathers JC, Strathdee G, Relton CL: Induction of epigenetic alterations by dietary and other environmental factors. Adv Genet 2010, 71:3-39.

32. Boom R, Sol CJ, Salimans MM, Jansen CL, Wertheim-van Dillen PM, van der Noordaa J: Rapid and simple method for purification of nucleic acids. $J$ Clin Microbiol 1990, 28:495-503.

33. Coombs NJ, Gough AC, Primrose JN: Optimisation of DNA and RNA extraction from archival formalin-fixed tissue. Nucleic Acids Res 1999, 27: e12.

34. Fachiroh J, Paramita DK, Hariwiyanto B, Harijadi A, Dahlia HL, Indrasari SR, Kusumo H, Zeng YS, Schouten T, Mubarika S, Middeldorp JM: Single-assay combination of Epstein-Barr Virus (EBV) EBNA1- and viral capsid antigenp18-derived synthetic peptides for measuring anti-EBV immunoglobulin $\mathrm{G}$ (IgG) and IgA antibody levels in sera from nasopharyngeal carcinoma patients: options for field screening. J Clin Microbiol 2006, 44:1459-1467.

35. Stevens SJ, Verkuijlen SA, Middeldorp JM: Quantitative detection of Epstein-Barr virus DNA in clinical specimens by rapid real-time PCR targeting a highly conserved region of EBNA-1. Methods Mol Biol 2005, 292:15-26.

36. Mizuno K, Osada H, Konishi H, Tatematsu Y, Yatabe Y, Mitsudomi T, Fujii Y, Takahashi T: Aberrant hypermethylation of the CHFR prophase checkpoint gene in human lung cancers. Oncogene 2002, 21:2328-2333.

37. Chang HW, Chan A, Kwong DL, Wei WI, Sham JS, Yuen AP: Detection of hypermethylated RIZ1 gene in primary tumor, mouth, and throat rinsing fluid, nasopharyngeal swab, and peripheral blood of nasopharyngeal carcinoma patient. Clin Cancer Res 2003, 9:1033-1038.

38. Herman JG, Graff JR, Myohanen S, Nelkin BD, Baylin SB: Methylationspecific PCR: a novel PCR assay for methylation status of CpG islands. Proc Natl Acad Sci USA 1996, 93:9821-9826.

39. Lo KW, Kwong J, Hui AB, Chan SY, To KF, Chan AS, Chow LS, Teo PM, Johnson PJ, Huang DP: High frequency of promoter hypermethylation of RASSF1A in nasopharyngeal carcinoma. Cancer Res 2001, 61:3877-3881.

40. Hesson LB, Wilson R, Morton D, Adams C, Walker M, Maher ER, Latif F: CpG island promoter hypermethylation of a novel Ras-effector gene RASSF2A is an early event in colon carcinogenesis and correlates inversely with Kras mutations. Oncogene 2005, 24:3987-3994.

41. Katzenellenbogen RA, Baylin SB, Herman JG: Hypermethylation of the DAP-kinase CpG island is a common alteration in B-cell malignancies. Blood 1999, 93:4347-4353.

42. Toyooka S, Toyooka KO, Harada K, Miyajima K, Makarla P, Sathyanarayana UG, Yin J, Sato F, Shivapurkar N, Meltzer SJ, Gazdar AF: Aberrant methylation of the $\mathrm{CDH} 13$ (H-cadherin) promoter region in colorectal cancers and adenomas. Cancer Res 2002, 62:3382-3386.

43. Overmeer RM, Henken FE, Snijders PJ, Claassen-Kramer D, Berkhof J, Helmerhorst TJ, Heideman DA, Wilting SM, Murakami Y, Ito A, et al: Association between dense CADM1 promoter methylation and reduced protein expression in high-grade CIN and cervical SCC. J Pathol 2008, 215:388-397.

44. Park HW, Kang HC, Kim IJ, Jang SG, Kim K, Yoon HJ, Jeong SY, Park JG: Correlation between hypermethylation of the RASSF2A promoter and Kras/BRAF mutations in microsatellite-stable colorectal cancers. Int J Cancer 2007, 120:7-12.

45. Overmeer RM, Louwers JA, Meijer CJ, van Kemenade FJ, Hesselink AT, Daalmeijer NF, Wilting SM, Heideman DA, Verheijen RH, Zaal A, et al: Combined CADM1 and MAL promoter methylation analysis to detect (pre-)malignant cervical lesions in high-risk HPV-positive women. Int J Cancer 2010, epub dec. 28.

doi:10.1186/1476-4598-10-48

Cite this article as: Hutajulu et al:: Epigenetic markers for early detection of nasopharyngeal carcinoma in a high risk population. Molecular Cancer 2011 10:48 